УДК 910.3(470)

ИНВЕСТИЦИИ В НАУЧНУЮ СФЕРУ РОССИИ: ТЕРРИТОРИАЛЬНЫЕ ОСОБЕННОСТИ, ПРОБЛЕМЫ И ТРЕНДЫ

Сафиуллин Р.Г.

Институт сочиильно-экономических исследований - обособленное структурное подразделение Федерального государственного бюджетного научного учреждения Уфимского федерального исследовательского иеетра Российской академии наук, Уфа, e-mail: SafiullinRG@yandex.ru

В статье рассматриваются современные проблемы развития научно-образовательной сферы России, важнейшей составляющей инновационной экономики. Период с 1970 по 2018 г. характеризуется быстрым ростом международной конкуренции в научно-образовательной сфере на глобальном уровне. В развитых странах мира объемы инвестиций в научную сферу постоянно увеличиваются. Отставание России от мировых лидеров по абсолютным объемам финансирования научной сферы увеличивается быстрыми темпами. В статье дан анализ территориальных особенностей в распределении внутренних текущих затрат, капитальных затрат на исследования и разработки, инвестиций на технологические инновации в производстве товаров, выполняемых работах и услугах в разрезе субъектов страны. Распределение фонда оплаты труда на научные исследования и разработки по субъектам страны характеризуется территориальной дифференциацией. В большинстве субъектов Центрального, Северо-Кавказского, Южного, Приволжского, Уральского, Сибирского федеральных округов оплата труда исследователей ниже среднего российского уровня. Проведена группировка субъектов страны по доле капитальных затрат на научные исследования от общих внутренних затрат. Наметился тренд по регионализации внутренних текущих инвестиций на научные исследования и разработки. Большинство субъектов страны имеют недостаточное финансирование по объемам капитальных затрат на научные исследования и разработки. Доля инвестиций на научные исследования и разработки в валовом внутреннем продукте страны за 2010-2018 гг. характеризуется трендом снижения. Объемы инвестиций в научную сферу России не соответствует масштабам экономики и не могут обеспечить достижение цели конкурентного инновационного социально-экономического развития на глобальном уровне.

Ключевые слова: научная сфера, научные инвестиции, внутренние затраты, капитальные затраты, территориальная концентрация, тренды

\title{
INVESTMENT IN THE RUSSIAN SCIENTIFIC SPHERE: TERRITORIAL FEATURES, PROBLEMS AND TRENDS
}

\section{Safiullin R.G.}

Institute of socio-economic research - a separate structural division of the Federal state budgetary scientific institution of the Ufa Federal research center

of the Russian Academy of Sciences, Ufa, e-mail: SafiullinRG@yandex.ru

The article deals with modern problems of development of the scientific and educational sphere of Russia, the most important component of the innovative economy. The period from 1970 to 2018 is characterized by a rapid increase in international competition in the field of science and education at the global level. In the developed countries of the world, the volume of investment in the scientific sphere is constantly increasing. Russia's lag behind the world leaders in terms of absolute volumes of funding for the scientific sphere is increasing rapidly. The article analyzes territorial features in the distribution of internal operating costs, capital expenditures for research and development, investments in technological innovations in the production of goods, works and services performed in the context of the country's subjects. The distribution of the wage Fund for research and development by the country's subjects is characterized by territorial differentiation. In most subjects of the Central, North Caucasus, southern, Volga, Ural, and Siberian Federal districts, researchers salaries are below the average Russian level. The country's subjects were grouped according to the share of capital expenditures on scientific research from total domestic expenditures. There is a trend towards regionalization of current domestic investment in research and development. Most of the country's subjects have insufficient funding in terms of capital expenditures for research and development. The share of investment in research and development in the country's gross domestic product for 2010-2018 is characterized by a downward trend. The volume of investment in the scientific sphere of Russia does not correspond to the scale of the economy and cannot ensure the achievement of the goal of competitive innovative socio-economic development at the global level.

Keywords: scientific sphere, scientific investments, internal expenditures, capital expenditures, territorial concentration, trends

Социально-экономическая конкурентоспособность мировых лидеров усиливается за счет стабильно возрастающего инвестирования в инновации и технологии будущего. Отставание России от мировых лидеров по абсолютным объемам финансирования научной сферы увеличивается быстрыми темпами. В связи с этим современные проблемы инновационного развития экономики России активно обсуждаются и исследуются учеными [1-3]. Анализ трансформации научно-образовательного пространства и оценка территориального распределения инвестиций на научные исследования и раз- 
работки в России имеет теоретико-прикладное значение в обеспечении территориальной эффективности хозяйства [4-6].

Цель исследования заключается в анализе проблем и территориальных закономерностей трансформации инвестиционного процесса в научно-образовательном пространстве России в разрезе субъектов и федеральных округов (ФО) с группировкой их на основе показателей капитальных инвестиций в научную сферу.

\section{Материалы и методы исследования}

Применены методы территориального и сравнительного анализа и оценки инвестиционного процесса в научно-образовательном пространстве России. Статья подготовлена на основе данных официальной статистики по научно-образовательной сфере России, а также использованы материалы научных публикаций по исследуемой проблеме [7-9].

\section{Результаты исследования и их обсуждение}

Общие объемы внутренних инвестиций в научную сферу России складываются из двух структурных составляющих. Первая инвестиционная составляющая это внутренние текущие затраты на научные исследования и разработки. Общий объем внутренних затрат в России на научные исследования и разработки в 2018 г. составил 1028,3 млрд рублей, и из них до 93,4\% приходились на внутренние текущие затраты на научные исследования и разработки (табл. 1).

На фонд оплаты труда научных работников приходится основная часть объемов внутренних текущих затрат на исследования и разработки $(60 \%)$. На обеспечение функционирования и содержания имущества научных организаций и центров расходуется $38 \%$ всего объема внутренних текущих затрат на исследования и разработки. На приобретение нового оборудования расходы достигали всего 2,0\%.

В территориальном распределении внутренних текущих затрат на исследования и разработки характерна высокая поляризация, обусловленная уровнем развития научно-образовательной сферы по регионам страны. На города Москва, С.-Петербург, Московскую и Нижегородскую области приходится до 65,3\% внутренних текущих затрат на исследования и разработки страны. Суммарная доля субъектов Северо-Кавказского, Южного и Дальневосточного ФО составляет 5,1\% от общих объемов внутренних текущих затрат на исследования и разработки страны. Более равномерный характер распределения объемов научных инвестиций в разрезе субъектов наблюдается в Приволжском, Уральском и Сибирском ФО.

Распределение фонда оплаты труда на научные исследования и разработки по субъектам страны повторяет территориальную картину локализации объемов внутренних текущих затрат. Среднемесячная оплата труда исследователей по России составила 70,5 тыс. рублей. Максимальные значения оплаты труда исследователей были характерны для Тюменской области, Республики Саха (Якутия), городов Москва, С.-Петербург. В большинстве субъектов Центральной России, Северо-Кавказского, Южного, Приволжского, Уральского, Сибирского ФО оплата труда исследователей ниже среднего российского уровня.

Дополнительные инвестиции на научные исследования и разработки, выделяемые по грантам Российского фонда фундаментальных исследований (РФФИ), существенной роли не играют. Бюджет РФФИ в 2018 г. был 22 млрд рублей, что составляет всего $2,1 \%$ от общих объемов внутренних инвестиций в научную сферу России.

Вторая инвестиционная составляющая - это капитальные затраты в научнообразовательную сфере на научные исследования и разработки. Общий объем капитальных затрат в России на научные исследования и разработки в 2018 г. составил 67,6 млрд рублей, или всего $6,6 \%$ от общих внутренних затрат на научные исследования и разработки.

На основе анализа территориальной дифференциации инвестиционного процесса в научно-образовательной сфере России (критерий: доля капитальных затрат на научные исследования и разработки от общих внутренних затрат на научные исследования и разработки (в среднем по стране 6,6\%)) выделены следующие группы регионов:

a) регионы, имеющие долю капитальных затрат более 7\%: Калининградская, Липецкая, Московская, Нижегородская, Псковская, Свердловская, Челябинская области, Пермский край (8 субъектов);

б) регионы, имеющие среднюю российскую долю капитальных затрат от 6 до $7 \%$ : г. Москва, Волгоградская, Вологодская, Ульяновская области (4 субъекта); 
в) регионы, имеющие долю капитальных затрат от $1 \%$ до менее $6 \%$. Самая многочисленная группа, насчитывающая 47 субъектов: города С.-Петербург и Севастополь, Архангельская, Белгородская, Воронежская, Ивановская, Калужская, Кировская, Ленинградская, Мурманская, Новгородская, Оренбургская, Пензенская, Ростовская, Рязанская, Самарская, Саратовская, Смоленская, Тамбовская, Тверская, Тюменская, Ярославская области, Респу- блики Башкортостан, Бурятия, Дагестан, Карелия, Коми, Крым, Мордовия, Саха (Якутия), Татарстан, Камчатский, Краснодарский, Красноярский, Приморский, Ставропольский, Хабаровский края и др.;

г) регионы, имеющие долю капитальных затрат менее 1\%: Астраханская, Владимирская, Курская, Магаданская, Омская, Орловская области, Республики Кабардино-Балкарская, Марий Эл, Алтайский край, Ханты-Мансийский АО (10 субъектов);

Внутренние текущие затраты на научные исследования и разработки и оплата труда исследователей в России по основным субъектам (2018 г.)*

\begin{tabular}{|c|c|c|c|c|c|}
\hline \multirow[t]{2}{*}{ Федеральные округа и субъекты } & \multicolumn{3}{|c|}{$\begin{array}{c}\text { Объем внутренних } \\
\text { текущих затрат, млрд руб. } \\
\end{array}$} & \multirow{2}{*}{$\begin{array}{c}\text { Численность } \\
\text { научных иссле- } \\
\text { дователей, тыс. } \\
\text { человек }\end{array}$} & \multirow{2}{*}{$\begin{array}{c}\text { Среднемесячная } \\
\text { оплата труда на- } \\
\text { учных исследова- } \\
\text { телей, тыс. руб. }\end{array}$} \\
\hline & Всего & \begin{tabular}{|c|}
$\begin{array}{c}\text { в т.Ч. фонд } \\
\text { заработной } \\
\text { платы }\end{array}$ \\
\end{tabular} & \begin{tabular}{|c|} 
Доля фонда \\
заработной \\
платы, \% \\
\end{tabular} & & \\
\hline Россия & 960,7 & \begin{tabular}{|l|}
577,2 \\
\end{tabular} & 60,1 & 682,6 & 70,5 \\
\hline Центральный ФО, в т.ч. & 491,9 & 303,8 & 61,8 & 341,9 & 74,1 \\
\hline Г. Москва & 328,8 & 205,4 & 62,5 & 204,9 & 83,5 \\
\hline Московская область & 114,7 & 71,3 & 62,2 & 86,8 & 68,5 \\
\hline Воронежская область & 7,9 & 4,9 & 62,0 & 11,0 & 37,1 \\
\hline Калужская область & 6,9 & 4,0 & 58,0 & 9,0 & 37,0 \\
\hline Северо-Западный ФО, в т.ч. & 135,6 & 84,3 & 62,2 & 91,7 & 76,6 \\
\hline Г. С.-Петербург & 117,7 & 70,7 & 60,1 & 75,0 & 78,6 \\
\hline Ленинградская область & 7,0 & 5,0 & 71,4 & 7,2 & 57,9 \\
\hline Южный ФО, в т.ч. & 25,1 & 16,4 & 65,3 & 26,4 & 51,8 \\
\hline Ростовская область & 12,6 & 8,1 & 64,3 & 11,7 & 57,7 \\
\hline Краснодарский край & 6,1 & 3,9 & 63,9 & 6,9 & 47,1 \\
\hline Северо-Кавказский ФО, в т.ч. & 5,1 & 3,4 & 66,7 & 7,0 & 40,5 \\
\hline Республика Дагестан & 1,1 & 0,9 & 81,8 & 1,6 & 46,9 \\
\hline Ставропольский край & 2,0 & 1,1 & 55,0 & 2,7 & 34,0 \\
\hline Приволжский ФО, в т.ч. & 149,2 & 79,4 & 53,2 & 104,9 & 63,1 \\
\hline Республика Башкортостан & 10,4 & 6,7 & 64,4 & 7,8 & 71,6 \\
\hline Республика Татарстан & 17,0 & 8,3 & 48,8 & 12,7 & 54,5 \\
\hline Пермский край & 12,8 & 7,3 & 57,0 & 9,9 & 61,5 \\
\hline Нижегородская область & 66,2 & 34,2 & 51,7 & 40,8 & 69,9 \\
\hline Самарская область & 13,8 & 7,9 & 57,3 & 10,0 & 65,8 \\
\hline Ульяновская область & 11,3 & 4,1 & 36,3 & 5,0 & 68,3 \\
\hline Уральский ФО, в т.ч. & 60,6 & 36,3 & 59,9 & 44,0 & 68,8 \\
\hline Свердловская область & 27,4 & 13,3 & 48,5 & 20,5 & 54,1 \\
\hline Тюменская область & 16,2 & 11,8 & 72,8 & 7,7 & 127,7 \\
\hline Челябинская область & 16,7 & 11,0 & 65,9 & 15,2 & 60,3 \\
\hline Сибирский ФО, в т.ч. & 74,8 & 40,7 & 54,4 & 52,5 & 64,6 \\
\hline Красноярский край & 22,0 & 6,9 & 31,4 & 7,9 & 72,8 \\
\hline Новосибирская область & 22,7 & 15,5 & 68,3 & 21,7 & 59,5 \\
\hline Томская область & 15,8 & 9,0 & 57,0 & 9,9 & 75,8 \\
\hline Дальневосточный ФО, в т.ч. & 18,3 & 13,1 & 71,6 & 14,2 & 76,9 \\
\hline Республика Саха (Якутия) & 2,9 & 2,4 & 82,8 & 2,1 & 95,2 \\
\hline Приморский край & 7,9 & 4,9 & 62,0 & 5,8 & 70,4 \\
\hline Хабаровский край & 2,3 & 1,6 & 60,6 & 1,8 & 74,1 \\
\hline
\end{tabular}

П р и м е ч а н и е . *Составлено и рассчитано автором по: [10, с. 998-1003]. 
Таблица 2

Капитальные затраты на научные исследования и разработки в России по основным субъектам (в текущих ценах, млн рублей)*

\begin{tabular}{|l|c|c|}
\hline \multicolumn{1}{|c|}{ Федеральные округа и субъекты } & 2018 & $\begin{array}{c}\text { Доля капитальных затрат от общих инвестиций в } \\
\text { научуюо сферу,\% }\end{array}$ \\
\hline Россия, млрд рублей & 67,6 & 6,61 \\
\hline Центральный ФО, млрд рублей, в т.ч. & 32,5 & 6,30 \\
\hline Г. Москва, млрд рублей & 22,1 & 7,74 \\
\hline Московская область, млрд рублей & 9,6 & 1,97 \\
\hline Воронежская область & 158 & 2,79 \\
\hline Калужская область & 199 & 5,25 \\
\hline Северо-Западный ФО, млрд рублей, в т.ч. & 7,4 & 5,43 \\
\hline Г. С.-Петербург, млрд рублей & 6,5 & \\
\hline Ленинградская область & 404 & 2,64 \\
\hline Южный ФО, в т.ч. & 907 & 3,11 \\
\hline Ростовская область & 342 & 5,35 \\
\hline Краснодарский край & 197 & 2,30 \\
\hline Северо-Кавказский ФО, в т.ч. & 117 & \\
\hline Республика Дагестан & 65 & 4,9 \\
\hline Ставропольский край & 48 & 4,21 \\
\hline Приволжский ФО, млрд рублей, в т.ч. & 15,6 & 11,67 \\
\hline Республика Башкортостан & 534 & 14,20 \\
\hline Республика Татарстан & 749 & 2,09 \\
\hline Пермский край & 1685 & \\
\hline Нижегородская область, млрд рублей & 11,0 & 8,84 \\
\hline Самарская область & 294 & 5,69 \\
\hline Уральский ФО, млрд рублей, в т.ч. & 8,4 & 22,31 \\
\hline Свердловская область & 2655 & 2,62 \\
\hline Тюменская область & 977 & 4,32 \\
\hline Челябинская область & 4784 & 3,11 \\
\hline Сибирский ФО, млрд рублей, в т.ч. & 2,3 & 1,14 \\
\hline Красноярский край & 594 & 1,20 \\
\hline Новосибирская область & 1026 & \\
\hline Томская область & 508 & 249 \\
\hline Дальневосточный ФО, в т.ч. & 33 & \\
\hline Республика Саха (Якутия) & 115 & \\
\hline Приморский край & 28 & \\
\hline Хабаровский край & & \\
\hline & & \\
\hline
\end{tabular}

П р и м е ч а н и е . *Составлено и рассчитано автором по: [10, с. 998-1009].

д) регионы, не имеющие капитальных затрат на научные исследования: Брянская, Костромская, Сахалинская, Тульская области, Республики Адыгея, Ингушетия, Калмыкия, Карачаево-Черкесская, Северная Осетия, Тыва, Чеченская, Алтай, Забайкальский край, Ненецкий АО (14 субъектов) (табл. 2).

Таким образом, в 14 субъектах капитальные затраты на научные исследования и разработки в 2018 г. отсутствовали, a 57 субъектов страны имели недостаточное финансирование по объемам капитальных затрат на научные исследования и раз- работки. В территориальном отношении почти $82 \%$ капитальных затрат на научные исследования и разработки концентрируются в пяти субъектах страны: гг. Москва, С.-Петербург, Нижегородская, Московская и Челябинская области. На субъекты Южного, Северо-Кавказского, Дальневосточного ФО приходится $1,95 \%$ капитальных затрат на научные исследования и разработки.

К косвенным инвестициям в научную сферу России относятся затраты на технологические инновации в экономику. Общий объем инвестиций на технологические инновации в России увеличился в теку- 
щих ценах с 1112 млрд рублей в 2013 г. до 1473 млрд рублей в 2018 г. Однако динамика удельного веса инвестиций на технологические инновации в общем объеме отгруженных товаров, выполненных работ и услуг за этот период характеризуется трендом снижения с 2,9\% до $2,1 \%$. Это свидетельствует о падении эффективности инвестиций, вкладываемых в технологические инновации. Эффективность инвестиций в технологические инновации в 2018 г. сохранили на уровне не ниже 2013 г. сле- дующие субъекты страны: Московская, Нижегородская, Омская, Пензенская, Сахалинская, Тамбовская, Томская, Ульяновская области, Республики Бурятия, Татарстан, Чувашская Республика, Хабаровский край (табл. 3).

Тенденция снижения эффективности инвестиций в технологические инновации объясняется в значительной мере экономическими санкциями, введенными развитыми странами, на экспорт передовых производственных технологий в Россию.

Инвестиции на технологические инновации в России по основным субъектам (в текущих ценах, млрд рублей)*

\begin{tabular}{|l|c|c|c|c|}
\hline \multicolumn{1}{|c|}{ Федеральные округа и субъекты } & 2013 & 2018 & \multicolumn{2}{|c|}{$\begin{array}{c}\text { Доля в общем объеме отгруженных } \\
\text { товаров, выполненных работ и услуг }\end{array}$} \\
\cline { 4 - 5 } & & & 2013 & 2018 \\
\hline Россия & 1112,4 & 1472,8 & 2,9 & 2,1 \\
\hline Центральный ФО, в т.ч. & 305,2 & 494,9 & 3,0 & 2,6 \\
\hline Г. Москва & 134,6 & 249,6 & 3,0 & 2,7 \\
\hline Московская область & 81,3 & 136,9 & 4,4 & 5,1 \\
\hline Калужская область & 15,6 & 10,4 & 3,5 & 1,3 \\
\hline Ярославская область & 13,1 & 4,7 & 5,4 & 1,2 \\
\hline Северо-Западный ФО в т.ч. & 164,2 & 133,3 & 3,7 & 1,6 \\
\hline Г. С.-Петербург & 63,8 & 94,2 & 3,6 & 2,5 \\
\hline Ленинградская область & 83,3 & 14,2 & 16,7 & 1,2 \\
\hline Южный ФО, в т.ч. & 45,2 & 41,1 & 2,2 & 1,1 \\
\hline Ростовская область & 20,4 & 19,6 & 3,2 & 1,8 \\
\hline Краснодарский край & 16,5 & 11,6 & 2,6 & 1,2 \\
\hline Северо-Кавказский ФО, в т.ч. & 5,6 & 7,1 & 1,5 & 0,8 \\
\hline Ставропольский край & 4,5 & 6,1 & 1,9 & 1,4 \\
\hline Приволжский ФО, в т.ч. & 284,9 & 397,3 & 3,6 & 3,0 \\
\hline Республика Башкортостан & 18,5 & 29,3 & 1,5 & 1,3 \\
\hline Республика Татарстан & 64,4 & 126,9 & 4,2 & 4,5 \\
\hline Пермский край & 37,9 & 36,9 & 3,4 & 2,2 \\
\hline Нижегородская область & 60,9 & 95,6 & 6,4 & 6,1 \\
\hline Самарская область & 65,8 & 42,5 & 6,3 & 2,8 \\
\hline Уральский ФО, в т.ч. & 130,9 & 142,5 & 1,8 & 1,2 \\
\hline Свердловская область & 40,9 & 39,8 & 2,7 & 1,8 \\
\hline Тюменская область & 58,1 & 73,6 & 1,2 & 0,9 \\
\hline Челябинская область & 31,1 & 28,3 & 3,3 & 1,7 \\
\hline Сибирский ФО, в т.ч. & 131,1 & 170,0 & 3,0 & 2,1 \\
\hline Красноярский край & 67,7 & 61,6 & 6,4 & 2,7 \\
\hline Иркутская область & 19,3 & 26,8 & 2,5 & 2,3 \\
\hline Омская область & 20,9 & 50,3 & 3,4 & 4,8 \\
\hline Дальневосточный ФО, в т.ч. & 45,4 & 86,5 & 2,5 & 2,5 \\
\hline Приморский край & 7,8 & 3,7 & 3,4 & 3,2 \\
\hline Хабаровский край & 6,9 & 12,8 & 3,3 & 5,4 \\
\hline Сахалинская область & 21,0 & 54,5 & 3,8 & \\
\hline & & & & \\
\hline
\end{tabular}

П р и м е ч а н и е . *Составлено и рассчитано автором по: [10, с. $1028-1031]$. 


\section{Выводы}

Динамика внутренних инвестиций в научную сферу России в текущих ценах характеризуется трендом роста. Но при этом доля инвестиций на научные исследования и разработки в валовом внутреннем продукте страны за 2010-2018 гг. уменьшилась с $1,13 \%$ до $0,98 \%$. В структуре внутренних затрат на научные исследования и разработки главной статьей расходов является оплата труда исследователей. В большинстве субъектов Центрального, Северо-Кавказского, Южного, Приволжского, Уральского, Сибирского ФО оплата труда исследователей ниже среднего российского уровня.

Абсолютное большинство субъектов страны (свыше 70) имеют недостаточное финансирование либо вовсе не имеют капитальных инвестиций на научные исследования и разработки. Свыше 80\% капитальных инвестиций на научные исследования и разработки сконцентрированы в пяти субъектах страны (гг. Москва, С.-Петербург, Нижегородская, Московская и Челябинская области).

Объемы инвестиций на технологические инновации в России в текущих ценах увеличиваются. Однако динамика удельного веса инвестиций на технологические инновации в экономике характеризуется трендом снижения.

Данное исследование выполнено в рамках государственного задания УФИЦ РАН № 075-01211-20-01 на 2020 2.

\section{Список литературы / References}

1. Бабурин В.Л. Инновационные циклы в российской экономике. М.: КРАСАНД, 2010. 216 с.

Baburin V.L. Innovation cycles in the Russian economy. M.: KRASAND, 2010. 216 p. (in Russian).

2. Бабурин В.Л., Земцов С.П. География инновационных процессов в России // Вестник Московского университета. Серия 5: География. 2013. № 5. С. 25-32.

Baburin V.L., Zemtsov S.P. Geography of innovation processes in Russia // Vestnik Moskovskogo universiteta. Seriya 5: Geografiya. 2013. No. 5. P. 25-32 (in Russian).

3. Сафиуллин Р.Г. Трансформация научно-образовательного пространства России: особенности, тренды, проблемы// Инновационные технологии управления социально-экономическим развитием регионов России: материалы XII Всероссийской научно-практической конференции с международным участием (Уфа, 27-28 августа 2020 г.). Уфа: ИСЭИ УФИЦ РАН, 2020.
Safiullin R.G. Transformation of the scientific and educational space of Russia: features, trends, problems // Innovatsionnyye tekhnologii upravleniya sotsial'no-ekonomicheskim razvitiyem regionov Rossii: materialy KHII Vserossiyskoy nauchno-prakticheskoy konferentsii s mezhdunarodnym uchastiyem (Ufa, 27-28 avgusta 2020 g.). Ufa: ISEI UFITS RAN, 2020 (in Russian).

4. Сафиуллин Р.Г., Сафиуллина Р.М. Эффективность территориального развития России: теория, реальность, проблемы // Инновационные технологии управления социально-экономическим развитием регионов России: материалы УІІ Всероссийской научно-практической конференции с международным участием. Пленарные доклады. Уфа: ИСЭИ УНЦ РАН, 2015. С. 37-47.

Safiullin R.G., Safiullina R.M. Efficiency of territorial development of Russia: theory, reality, problems // Innovatsionnyye tekhnologii upravleniya sotsial'no-ekonomicheskim razvitiyem regionov Rossii: materialy UII Vserossiyskoy nauchno-prakticheskoy konferentsii s mezhdunarodnym uchastiyem. Plenarnyye doklady. Ufa: ISEI UNTS RAN, 2015. P. 3747 (in Russian).

5. Гаджиев М.М., Бучаев Я.Г., Яковлева Е.А. Финансовое обеспечение научных разработок в России // Вопросы структуризации экономики. Махачкала: Научно-аналитический центр «Этноэкономика», 2013. № 3. С. 34-39.

Gadzhiev M.M., Buchaev Ya.G., Yakovleva E.A. Financial support of scientific developments in Russia // Voprosy strukturizatsii ekonomiki. Makhachkala: Nauchno-analiticheskiy tsentr «Etnoekonomika», 2013. No. 3. P. 34-39 (in Russian).

6. Чех В.В. Механизмы инвестиций в сферу образования: проблемы и решения // Вопросы образования. М.: НИУ «Высшая школа». 2010. № 1. С. 134-151.

Chekh V.V. Mechanisms of investment in education: problems and solutions // Voprosy obrazovaniya. M.: NIU «Vysshaya shkola». 2010. No. 1. P. 134-151 (in Russian).

7. Сафиуллин Р.Г. Территориально-структурная организация научно-образовательной сферы России // Успехи современного естествознания. 2020. № 9. С. 94-99.

Safiullin R.G. Territorial and structural organization of the scientific and educational sphere of Russia // Uspekhi sovremennogo yestestvoznaniya. 2020. No. 9. P. 94-99 (in Russian).

8. Миндели Л.Э., Черных С.И. Финансирование фундаментальных исследований в России. М.: ИПРН РАН, 2017. $44 \mathrm{c}$.

Mindeli L.E., Chernykh S.I. Financing of fundamental research in Russia. M.: IPRN RAN, 2017. 44 p. (in Russian).

9. Молчан А.С., Погребная Н.В., Суринина Ю.В. Российская сфера НИОКР: современные инвестиционные реалии // Политематический сетевой электронный научный журнал Кубанского государственного аграрного университета. Краснодар, 2016. № 123. C. 1544-1554.

Molchan A.S., Pogrebnaya N.V., Surinina Yu.V. Russian R \& d sphere: modern investment realities // Politematicheskiy setevoy elektronnyy nauchnyy zhurnal Kubanskogo gosudarstvennogo agrarnogo universiteta. Krasnodar, 2016. No. 123. P. 1544 1554 (in Russian).

10. Регионы России. Социально-экономические показатели. 2019: Р32 Статистический сборник. М.: Росстат, 2019. 1204 c.

Region of Russia. Socio-economic indicators. 2019: P32 Statistical collection. M.: Rosstat, 2019. 1204 p. (in Russian). 